\title{
Challenge Demands and Resilience
}

\section{Strain and Learning as Different Pathways}

\author{
Arian Kunzelmann ${ }^{1}$ and Thomas Rigotti ${ }^{1,2}$ \\ ${ }^{1}$ Psychological Institute, Department of Work-, Organizational- and Business Psychology, Johannes Gutenberg University Mainz, Germany \\ ${ }^{2}$ Leibniz Institute for Resilience Research (LIR), Mainz, Germany
}

\begin{abstract}
This study investigates the relationship of challenge demands (i. e., time pressure, job complexity) on employee resilience. We provide insights into potential pathways (i.e., learning, cognitive irritation) for how challenge stressors influence employee resilience. We employed a two-wave, time-lagged design to examine the influences of challenge stressors and explanatory pathways on employee resilience 2 months later. The data from 359 participants (52.1\% male) were analyzed using a Bayesian time-lagged path model. Results indicate that time pressure and job complexity are negatively related to employee resilience via cognitive irritation. In contrast, we found a positive, indirect effect of job complexity and resilience via learning. This paper contributes to existing employee resilience and stress research by highlighting the roles of learning and cognitive irritation to explain the relationships of challenge stressors on employee resilience. Moreover, the results provide us with a deeper understanding of which factors foster or drain employee resilience.
\end{abstract}

Keywords: stress, job demands, resilience, resources, learning

Challenge Stressoren und Resilienz: Beanspruchung und Lernen als unterschiedliche Erklärungspfade

Zusammenfassung: Die vorliegende Studie untersucht die Beziehung von Challenge Stressoren (Zeitdruck, Arbeitskomplexität) und der Resilienz von Erwerbstätigen. Diese Studie gibt Einblicke zu möglichen Mediatoren (Lernerfahrungen, kognitive Irritation), wie Challenge Stressoren die Resilienz beeinflussen. In einem time-lagged-Design wurden die Einflüsse von Challenge-Stressoren und den erklärenden Mediatoren auf die Resilienz zwei Monate später untersucht. Daten von 359 Personen ( $52.1 \%$ männlich) wurden für die Analysen in einem Bayesian time-lagged-Pfadmodell verwendet. Die Ergebnisse zeigten, dass Zeitdruck und Arbeitskomplexität einen indirekten negativen Zusammenhang mit Resilienz vermittelt über kognitive Irritationen aufwiesen. Demgegenüber wies Arbeitskomplexität auch einen indirekt positiven Zusammenhang mit Resilienz vermittelt über Lernerfahrungen auf. Die Studienergebnisse tragen zu Erkenntnissen der Resilienzund Stressforschung bei und heben die Bedeutung von vermittelnden Mediatoren besonders hervor. Darüber hinaus tragen die Studienbefunde zu einem besseren Verständnis der Faktoren bei, welche die Resilienz fördern oder verringern.

Schlüsselwörter: Stress, Arbeitsanforderungen, Resilienz, Ressourcen, Lernerfahrungen

The concept of employee resilience has gained momentum as an important factor in maintaining the psychological functioning of employees under stressful conditions (Britt et al., 2016; King et al., 2016). Employee resilience can be described as the capacity to utilize resources to maintain optimal psychological functioning and to adapt and thrive when faced with adverse conditions at work (Kuntz et al., 2016). Previous research provides evidence that challenge demands have a positive and hindrance demands a negative relationship with employee resilience (Crane \& Searle, 2016). A delineation of job demands into challenges and hindrances is based on the challengehindrance framework (Cavanaugh et al., 2000; LePine et al., 2005), which states that hindrance demands are classified as obstacles for personal growth and goal achievement, whereas challenge demands represent demands that, although still straining, facilitate personal gains and development (LePine et al., 2005; Prem et al., 2017). In particular, challenge demands such as time pressure and job complexity have the potential to promote personal growth, learning, and motivation (e.g., Crawford et al., 2010). The systematic self-reflection model of resilience strengthening (SSR; Crane, Searle et al., 2019) acknowledges that individuals can use stressful demands as opportunities to facilitate resilience, such that specific stressors trigger experiences of learning that contribute to experiences of personal growth. Even though positive relationships with challenge demands and employee resilience have been reported (Crane \& Searle, 2016), the investigation of mediators to explain how challenge 


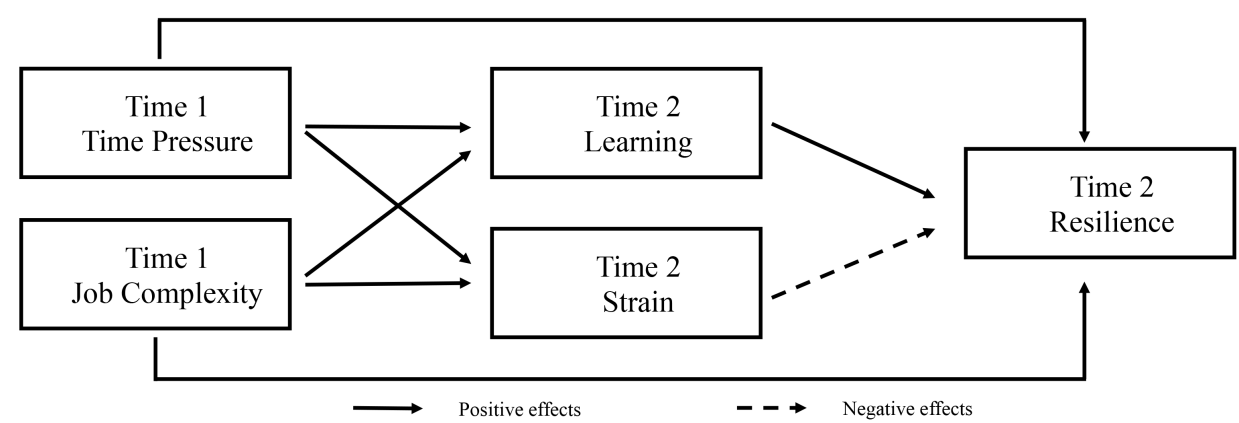

demands are positively linked with employee resilience is still pending, representing an important contribution to existing research.

This paper explores the effects of time pressure and job complexity as typical challenge demands (e.g., Liu \& Li, 2018; Prem et al., 2018). They represent central demands from prominent occupational models of stress or within an integrative typology of job characteristics, such as time pressure in the job-demand-control model (Karasek, 1979) and job complexity in conceptualizations of the work design questionnaire (WDQ; Morgeson \& Humprehy, 2006). Moreover, it examines potential mediators in an effort to broaden our understanding of how challenge stressors affect employee resilience. We used the challenge-hindrance stressor framework (Cavanaugh et al., 2000) and the SSR model (Crane, Searle et al., 2019) to explore how time pressure and job complexity influence employee resilience. Based on the ambivalent nature of challenge stressors, which can trigger experiences of both personal growth and psychological job strain (LePine et al., 2005), it represents a fruitful avenue for integrating these two dimensions as mediators and enabling a deeper understanding of how challenge stressors affect employee resilience. We focused on learning as the cognitive component of personal growth characterized by the acquisition of knowledge and skills (Porath et al., 2012), which has been positively associated with challenge demands (Prem et al., 2017). Psychological job strain represents "the result of a disturbance of the equilibrium between the demands employees are exposed to and the resources they have at their disposal" (Bakker \& Demerouti, 2014, p. 310). Moreover, we used cognitive irritation, consisting of ruminative thoughts about problems at work and a lack of the ability to mentally detach from work (Mohr et al., 2005).

By testing pathways that link certain stressors to employee resilience, this study extends our knowledge of how challenge stressors affect employee resilience and thus contributes to a theoretical refinement of the challenge-hindrance framework as well as resilience research. To the best of our knowledge, this is the first study to investigate mechanisms linking challenge demands with employee resilience. Moreover, such an approach goes beyond and extends previous research findings and demonstrates that resilience is not restricted to the exposure of adverse/traumatic events (cf. Crane, Searle et al., 2019; Crane \& Searle, 2016). We hereby draw on theoretical considerations from the SSR model (Crane, Searle et al., 2019), by providing evidence of which pathways (i.e., learning, cognitive irritation) link stressors to employee resilience, and we provide practical implications for job-design and targeted intervention programs within organizations. Figure 1 illustrates the conceptual research model.

\section{The Construct of Employee Resilience}

With the construct of employee resilience, it is important to distinguish between the demonstration of resilience and the capacity for resilience (Britt et al., 2016). The demonstration of resilience signifies that an individual shows positive adaptation after a significant adverse or stressful event, consisting of maintaining physiological and psychological health or psychological functioning (Britt et al., 2016; Crane, Searle et al., 2019). Conversely, the capacity for resilience reflects the availability of resources and protective factors that modify the relationship between stressor exposure and psychological outcomes (e.g., wellbeing, clinical symptoms; Britt et al., 2016). The capacity for resilience includes coping strategies (e.g., cognitive and behavioral attempts to cope with upcoming demands), personal and/or contextual resources (e.g., selfefficacy, social support), and approaches of emotion regulation (e.g., situation modification; Gross, 2015) that contribute to an increased likelihood of resilient outcomes (Crane, Searle et al., 2019).

Recent resilience research within the organizational context has focused on employees who experience sig- 
nificant adverse events, for example in the military (e.g., Crane, Boga et al., 2019). However, employee resilience is not restricted to significant adversity but also likely affected by exposure to relevant daily stressors at work. The theoretical self-reflection model of resilience strengthening (Crane, Searle et al., 2019) underpins this assertion and proposes that resilience may be influenced through potentially traumatic events as well as everyday stressors. This model accounts for the resilience-strengthening effect of daily stressors through learning about one's reactions to stress over time and through adapting coping strategies, reappraising, or enhancing psychological resources (i.e., self-efficacy; Crane et al., 2020; Crane, Searle et al., 2019). The likelihood of learning experiences may be even higher for everyday stressors, compared to traumatic events (Crane, Searle et al., 2019), which is supported by research on stress inoculation (Meichenbaum, 1985; Meichenbaum \& Deffenbacher, 1988). Moreover, a recent meta-analysis regarding the reciprocal long-term effects of job stressors and burnout showed that, over time, the effects of job stressors on burnout were smaller than the effect of burnout on job stressors (strain effect), and that this strain effect is buffered by available resources (i.e., job control, social support; Guthier et al., 2020). Regarding the availability of resources, resilience influences perceptions of stressors, such that resilient individuals appraise stressful conditions as less threatening and also show higher positive emotionality (Tugade \& Fredrickson, 2004). Thus, an investigation of potential antecedents of employee resilience represents an important aspect to better understand which factors contribute to its development, and it enables employees to reduce threat appraisal processes related to upcoming job stressors (cf. Guthier et al., 2020).

\section{Challenge Stressors as Antecedents of Employee Resilience}

The challenge-hindrance framework distinguishes between challenge and hindrance demands (Cavanaugh et al., 2000). Challenge demands have the potential to promote personal growth and trigger a motivational process that results in an increase in performance and engagement (Cavanaugh et al., 2000; Podsakoff et al., 2007); examples of challenge demands are time pressure, job complexity, workload, and learning demands (Cavanaugh et al., 2000; LePine et al., 2005). In contrast, hindrance demands are linked only to negative work outcomes, as they drain personal resources and prevent personal accomplishment and development (Cavanaugh et al., 2000); examples of hindrance demands are job insecurity, red tape, role conflicts, and role ambiguity (Podsakoff et al., 2007). Like hindrance stressors, challenge stressors have an energy-depleting character, but they can trigger a developmental process to increase personal capabilities at the same time (Podsakoff et al., 2007; Widmer et al., 2012).

Prem et al. (2017) showed that challenge stressors were positively associated with learning. In a longitudinal study, Crane and Searle (2016) found that challenge demands facilitate and hindrance demands drain the resilience of employees. To theoretically underpin the positive effects of challenge stressors, we can draw on the SSR model (Crane, Searle et al., 2019). It is likely that exposure to challenge stressors increases context sensitivity to demands and stimulates a positive future mindset in triggering self-reflective practices (e.g., reappraisal, stressor evaluation), whereas the translation of hindrance stressors into opportunities for personal development might be undermined, as they do not create an initial process of learning adaptation (Crane \& Searle, 2016; Crane, Searle et al., 2019).

Even though empirical findings support the idea of a two-dimensional delineation of demands into challenges and hindrances (LePine et al., 2005), doubts have been raised regarding the favorable effects of challenge demands (Mazzola \& Disselhorst, 2019). Research that focused on singular demands considered as challenges showed variation regarding the positive effects of such demands on work outcomes (Baethge et al., 2018). Thus, focusing on specific challenge demands is relevant in this research context, as it contributes to a nuanced differentiation of challenge stressor exposure and employee resilience (cf. Crane \& Searle, 2016). In this paper, we chose to study time pressure and job complexity because they represent typical challenge stressors based on previous research findings (LePine et al., 2005; Liu \& Li, 2018) and are central components of prominent occupational stress models (i. e., time pressure; Karasek, 1979) or integrative typologies of job characteristics (i.e., job complexity; Morgeson \& Humphrey, 2006). Moreover, time pressure and job complexity are shown to be strong catalysts for challenge perceptions, emphasizing mastery, goal accomplishment, and experiences of growth (Liu \& Li, 2018; Prem et al., 2018). Experienced time pressure is characterized by feelings of insufficient time to complete tasks or projects or that one should work faster than usual (Baer \& Oldham, 2006; Teuchmann et al., 1999). Job complexity is defined as the extent of difficulty and complexity related to tasks at work. Complex tasks are mentally more demanding and require a higher skill level to perform the job effectively (Morgeson \& Humphrey, 2006). 
We propose a positive effect of time pressure and job complexity on employee resilience, as they potentially provide the opportunity for growth, triggering experiences of learning and personal development (cf. Crane, Searle et al., 2019). This is based on the assumption that these two stressors provide a challenging work environment and, as a result, facilitate a process of personal development (Hargrove et al., 2013). Therefore, we propose the following:

Hypothesis 1: Time pressure (H1a) and job complexity (H1b) show a positive relationship with employee resilience.

\section{Learning and Cognitive Irritation as Explanatory Mechanisms}

We focus on cognitive irritation as an indicator of strain and learning as an indicator for personal growth to investigate pathways for how challenge stressors affect employee resilience. Cognitive irritation includes rumination processes about problems at work and is defined as a reduced self-regulation capacity related to a lack of ability to mentally detach from work (Mohr et al., 2005). Time pressure increases cognitive irritation (e.g., Widmer et al., 2012), and cognitive irritation is a good indicator of workrelated strain (Rigotti et al., 2014). Based on the theoretical assumptions of the challenge-hindrance framework (Cavanaugh et al., 2000) and the JD-R theory (Bakker \& Demerouti, 2017) about the health-impairment character of experienced job demands, we propose a positive effect of time pressure and job complexity on cognitive irritation. This relationship is in line with propositions of the stressor-detachment model (Sonnentag \& Fritz, 2015), which suggests that being exposed to job stressors reduces the opportunity to mentally detach from work, resulting in a lack of recovery processes. Job stressors are negatively related to psychological detachment, and psychological detachment mediates the relationship between job stressors and indicators of strain, such as emotional exhaustion and need for recovery (Sonnentag et al., 2010). Additionally, we suggest that, as an indicator of reduced psychological detachment, cognitive irritation is negatively linked to employee resilience. Empirical research has shown a negative relationship between resilience and burnout (Hao et al., 2015), as well as with psychological strain (Crane \& Searle, 2016). The stressordetachment model (Sonnentag \& Fritz, 2015) posits that a lack of mental detachment from work restricts recovery processes during off-job time, resulting in a failure to replenish psychological resources. Following this, we assume that cognitive irritation is negatively associated with employee resilience, and that challenge stressors specifically time pressure and job complexity - promote an increase in cognitive irritation. Therefore, we propose the following:

Hypothesis 2: Time pressure (H2a) and job complexity (H2b) have a negative indirect relationship on employee resilience via cognitive irritation.

We further propose a positive indirect effect of challenge demands (i.e., time pressure, job complexity) and employee resilience via learning. Learning is characterized by the acquisition of knowledge and skills, representing an important psychological component of personal growth (Porath et al., 2012). Based on the assumptions of the challenge-hindrance framework, challenge stressors can trigger a process of learning, motivation, personal growth, and flourishing (Kim \& Beehr, 2020; LePine et al., 2005). Accordingly, recent refinements on the JD-R theory also support the idea that experienced challenging demands might affect favorable outcomes, such as work engagement and flourishing through a motivational process (Bakker \& Demerouti, 2017). Consequently, challenge stressors should facilitate learning experiences, as they trigger a motivational process. Further, learning should be positively associated with employee resilience. Porath et al. (2012) discussed potential relationships of learning to other related constructs within positive organizational behavioral research, such as psychological capital (a second-order construct including resilience, hope, optimism, and self-efficacy; cf. Youssef \& Luthans, 2007). For example, Flinchbaugh et al. (2015) showed a positive association between resilience and thriving at work (including learning and vitality; cf. Porath et al., 2012). We argue that challenge stressors (i.e., time pressure and job complexity) are related to perceptions of learning, which in turn positively influences employee resilience. Explicitly, a higher sense of learning facilitates the accumulation of additional personal resources, such as employee resilience (cf. Hobfoll, 1989). Thus, we propose the following:

Hypothesis 3: Time pressure (H3a) and job complexity (H3b) have a positive indirect relationship on employee resilience via learning.

\section{Method}

\section{Participants and Design}

Data were collected at two timepoints with an 8-week interval to separate the measurement of the outcome variables (i.e., resilience, learning, and cognitive irritation) from the predictors (i.e., time pressure, job complexity) to minimize common method bias (Podsakoff et al., 2003). A time interval of several weeks was successfully 
applied in occupational stress literature (Crane \& Searle, 2016; Kim \& Beehr, 2020). Considering the effects of job demands on learning and cognitive irritation with a time element is important. Previous studies showed that associations between occupational stressors and psychological strain strengthen over time (e.g., Ford et al., 2014), and that learning processes are not immediately linked to stressor exposure, but rather it is a process that evolves based on individual stressor evaluations (Crane, Searle et al., 2019). Thus, we also timely separated job demands and the proposed mediators (i.e., learning, cognitive irritation) to adequately examine our implicit assumptions that link job demands to employee resilience.

The data represent a convenience sample and were collected through private networks and within an international company. At T1, 1,800 paper-and-pencil questionnaires were sent for internal distribution to the headquarters of the participating international company. Further, undergraduate students acquired participants by distributing a link to an online survey platform. At T1, 442 participants from the company filled out the questionnaire (response rate $=24.6 \%$ ), though 65 participants had failed to indicate their agreement to the study conditions and were excluded. Additionally, 255 persons participated at $\mathrm{T} 1$ in the online survey, but 3 had to be excluded because of missing values on all variables. Thus, at $\mathrm{T} 1$ we collected data from 629 participants. To determine potential differences between the different data sources in demographics and the variables measured at $\mathrm{T} 1$, we ran a chi-square test for sex as well as additional independent $t$-tests. Results indicated that more men worked in the international company (94.8\% male) compared to individuals from the online survey $(35.1 \%$ male), $\left(x^{2}=245.72, p<.001\right)$. Additionally, the sample from the international company was slightly older $(M=$ $6.50, S D=2.45)$ than the sample from the online survey $(M=4.96, S D=2.36), t=-7.84, p<.01$; whereas participants from the online survey showed a higher job complexity $(M=4.15, S D=0.65$ vs. $M=3.74, S D=0.86$; $t=7.23, p<.001)$ and also a higher resilience $(M=5.32$, $S D=0.79$ vs. $M=5.12 ; t=2.28, p=0.02$ ). There was no significant difference in the amount of experienced time pressure between the international company and the participants of the online survey $(M=3.11, S D=0.85, M$ $=3.01, S D=0.92 ; t=-0.59, p=.55$, respectively). At T2, 307 individuals could be matched using a participantgenerated survey code (response rate: $48.8 \%$ ).

To test for potential systematic attrition between timepoints, we ran binomial logistic regressions (backward method). The results indicated that remaining participants tended to be female, $\operatorname{Exp}(B)=.29, p<.001$, to experience a higher amount of time pressure, $\operatorname{Exp}(B)=$ $1.32, p=.011$, and to have a lower amount of job complexity $\operatorname{Exp}(B)=.62, p<.001$. Neither age nor resilience showed significant differences between responders and nonresponders. By applying Bayesian computation technique (Hoijtink et al., 2019), we were able to use data from 359 participants for our analyses (30.4\% from the international company, $69.6 \%$ from the online survey), yielding the final sample size. The age and work experience of the participants had to be clustered because of data-security concerns of the participating company. Within this final sample of 359 participants $(52.1 \%$ male, $32.6 \%$ had a leadership position), $3.1 \%$ were older than 60 years, $6.7 \%$ between $56-60,15.6 \%$ between 51 to 55 , $14.2 \%$ between 46 to $50,10.9 \%$ between $41-45,8.1 \%$ between $36-40,13.1 \%$ between $31-35,13.6 \%$ between $26-30,11.4 \%$ between $21-25$, and $3.3 \%$ between $15-20$ years of age. The average working time was 35.70 hours $(S D=7.16)$ per week with a predominant tenure of more than 20 years of working experience $(44.8 \%)$. The largest group of the participants $(57.7 \%)$ worked in private companies, $22 \%$ were employed in private or public institutions (labeled as "other"), $17.8 \%$ worked for public services, and $2.5 \%$ for religious institutions.

\section{Measures}

\section{Time Pressure}

Time pressure was assessed at $\mathrm{T} 1$ with five items from the Instrument for Stress-Oriented Job Analysis (Semmer et al., 1999) on a Likert scale ranging from $1=$ seldom to $5=$ very often (e.g., "Do you have to work long hours in order to fulfill your work?"). Cronbach's alpha was .86.

\section{Job Complexity}

Job complexity was assessed at $\mathrm{T} 1$ with a validated German version of the Work Design Questionnaire (Stegmann et al., 2010; cf. Morgeson \& Humphrey, 2006). Job complexity consisted of four items answered on a Likert scale ranging from $1=$ strongly disagree to $5=$ strongly agree (e.g., "The job requires that I only do one task or activity at a time," reverse coded). Cronbach's alpha was .73.

\section{Cognitive Irritation}

Cognitive irritation was assessed at T2 with the Irritation Scale (Mohr et al., 2005), consisting of three items (e.g., "Even at home, I often think of my problems at work."). A 7-point Likert scale was used ranging from 1 = strongly disagree to $7=$ strongly agree and the scale yielded a reliability of .89 . 


\section{Learning}

Learning was measured at $\mathrm{T} 2$ with five items from the English version of the Thriving at Work Scale developed by Porath et al. (2012). The items were translated into German using the backtranslation approach (Brislin, 1970) and were answered on a 7-point Likert scale ranging from 1 = strongly disagree to 7 = strongly agree (e.g., "At work, I continue to learn more and more as time goes by."). The scale yielded a reliability of .92 .

\section{Resilience}

Resilience was measured at $\mathrm{T} 1$ and $\mathrm{T} 2$ with 10 items from a validated German version of the Connor-Davidson Resilience Scale (CD-RISC; Sarubin et al., 2015; cf. Connor \& Davidson, 2003). The CD-RISC was chosen as it represents a widely used scale to assess resilience with good psychometric properties and has been also proved to capture temporal changes (Rees et al., 2015; Windle et al., 2011). Moreover, the CD-RISC focuses on measuring protective factors and available resources (e.g., problemsolving skills) beyond the assessment of trait-like aspects only, such as hardiness (Connor \& Davidson, 2003; Rees et al., 2015). Thus, this scale fits our study purposes as it captures modifiable state-like aspects and changes in resilience over time. Items were answered on a 7-point Likert scale ranging from $1=$ strongly disagree to $7=$ strongly agree. A sample item is "I can deal with whatever comes my way." Cronbach's alpha was .87 and .88 for T1 and $\mathrm{T} 2$, respectively.

\section{Control Variables}

We used age and sex as control variables to prevent potential alternative explanations of the study results. A previous meta-analysis (Hu et al., 2015) showed that age and sex interact with resilience and mental health outcomes, revealing that resilience increases with age, and that women report a lower level in the heritability of resilience than men.

\section{Confirmatory Factor Analyses}

To test whether our investigated constructs were distinct from each other and to support the assumed six-factor structure of our model (see Figure 1), we ran a set of confirmatory factor analyses. A one-factor model clearly showed a worse fit $\left(\chi^{2}=4435.95, d f=619, C F I=.466, T L I\right.$ $=.420$, RMSEA $=.127)$ than a six-factor model $\left(\chi^{2}=\right.$ 1269.86, $d f=613, C F I=.907, T L I=.899, R M S E A=.053$; $\left.\Delta \chi^{2}=3166.09, \Delta d f=6, p<.001\right)$. In addition, the sixfactor model (in this model we fixed the factor loadings of same items of resilience at $\mathrm{T} 1$ and $\mathrm{T} 2$ to be equal and correlated the same items at $\mathrm{T} 1$ and $\mathrm{T} 2$ ) showed superior fit indices than a five-factor model that combined learning and resilience at $\mathrm{T} 2$ in one factor $\left(\chi^{2}=2386.01, d f=618\right.$,
$C F I=.750, T L I=.731, R M S E A=.086 ; \Delta \chi^{2}=1113.05, d f=$ $4, p<.001)$. A five-factor model was also considered, as resilience and learning are interrelated (Carver, 1998; Crane, Searle et al., 2019).

\section{Data Analysis}

To investigate the effects of stressors on resilience and potential mediators, we employed a time-lagged path model using Mplus Version 7.3 (Muthén \& Muthén, 19982014). We used a Bayesian estimation approach as a suitable computation technique with default (noninformative) priors and a Markov chain Monte Carlo algorithm to conduct the path model (Kaplan \& Depaoli, 2015). Using Bayesian estimators is suitable because of the often-skewed distribution of indirect effects (Prem et al., 2018). We used means for point estimates and the Bayesian credibility intervals (CI) for the indirect relationships. In our model, time pressure and job complexity were the predictors at $\mathrm{T} 1$, learning and cognitive irritation were the mediators at $\mathrm{T} 2$, and resilience at $\mathrm{T} 2$ was the outcome variable (controlled for resilience at T1).

\section{Results}

\section{Preliminary Analyses}

Table 1 represents the descriptives and bivariate correlations of the study variables. T1 time pressure and T1 job complexity had a positive relationship with $\mathrm{T} 2$ cognitive irritation $(r=.38, p<.001 ; r=.31, p<.001$, respectively). However, only $\mathrm{T} 1$ job complexity showed a positive relationship with T2 learning $(r=.23, p<.001)$, whereas we found no significant relationship between T1 time pressure and T2 learning $(r=.06, p=.33)$. Neither T1 time pressure nor $\mathrm{T} 1$ job complexity showed a significant relationship with T2 resilience $(r=.04, p=.55 ; r=.06, p$ $=.27$, respectively).

\section{Hypothesis Testing}

We tested our hypotheses in a single Bayesian timelagged path model. To predict changes in resilience, we included resilience at $\mathrm{T} 1$ as a predictor for resilience at $\mathrm{T} 2$. Figure 2 illustrates the computed Bayesian estimates from the path model, and Table 2 summarizes the results. Contrary to Hypothesis 1a, time pressure at $\mathrm{T} 1$ showed no significant positive total relationship with employees' resilience at T2, $b=-.02$, 95\% Bayesian CI [-.10, .04]. Job complexity at $\mathrm{T} 1$ also showed no significant positive total relationship with employee resilience at $\mathrm{T} 2, b=.02$, 
Table 1. Descriptive statistics and bivariate correlations of study variables

\begin{tabular}{|c|c|c|c|c|c|c|c|c|c|c|}
\hline Variable & $M$ & $S D$ & 1 & 2 & 3 & 4 & 5 & 6 & 7 & 8 \\
\hline 1. T1 Time Pressure & 3.06 & 0.91 & $(.86)$ & & & & & & & \\
\hline 2. T1 Job Complexity & 4.06 & 0.72 & $.38 * \star$ & (.73) & & & & & & \\
\hline 3. T2 Cognitive Irritation & 3.58 & 1.70 & $.38 * *$ & $.31 * *$ & $(.89)$ & & & & & \\
\hline 4. T2 Learning & 4.99 & 1.20 & .06 & $.23 * *$ & -.06 & $(.92)$ & & & & \\
\hline 5. T1 Resilience & 5.30 & 0.82 & .05 & $.11 *$ & $-.17 * \star$ & $.27 \star \star$ & $(.87)$ & & & \\
\hline 6. T2 Resilience & 5.23 & 0.85 & .04 & .06 & $-.31 * *$ & $.30 * \star$ & $.77 *$ & $(.88)$ & & \\
\hline 7. Age $^{1}$ & 5.40 & 2.45 & .10 & $.16^{* *}$ & .07 & .05 & .04 & -.03 & - & \\
\hline 8. Gender ${ }^{2}$ & 0.48 & 0.50 & .00 & .07 & .08 & .00 & -.08 & -.01 & $-.22 \star \star$ & - \\
\hline
\end{tabular}

Note. ${ }^{1}$ Age $(1=15-20$ years, $2=21-25$ years, $3=26-30$ years, $4=31-35$ years, $5=36-40$ years, $6=41-45$ years, $7=46-50$ years, $8=51-55$ years, $9=$ $56-60$ years, $10=>60$ years); ${ }^{2}$ Sex $(0=$ male, $1=$ female $) .{ }^{*} p<.05, * * p<.001$.

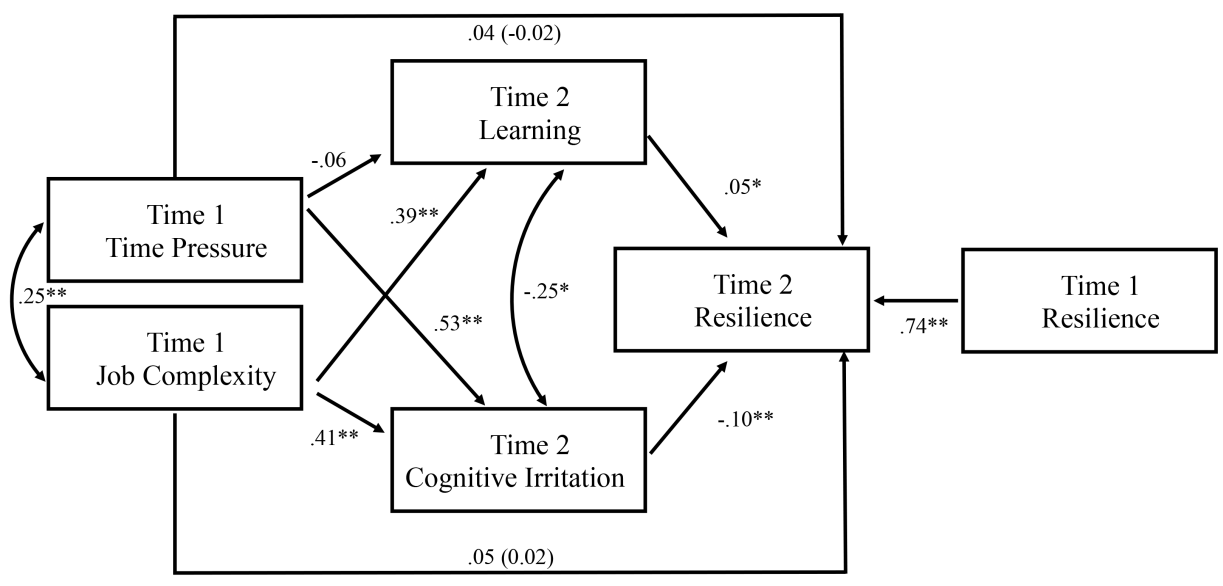

\begin{abstract}
Note. This figure shows unstandardized estimates. Estimates are controlled for age and sex. The estimates in parentheses indicate the total relationships between time pressure and job complexity on resilience. ${ }^{*} p<.05,{ }^{* \star} p<.001$.
\end{abstract}

Figure 2. Estimates from Bayesian time-lagged path model.
95\% Bayesian CI [-.05, .12]. Thus, Hypotheses 1a and 1b were not supported and had to be rejected. However, T1 time pressure showed a significant positive relationship with $\mathrm{T} 2$ cognitive irritation, $b=.53,95 \%$ Bayesian CI [.40, .76], albeit no significant positive relationship with T2 learning, $b=-.06,95 \%$ Bayesian CI [-.18, .10]. Further, T1 job complexity showed a significant positive relationship with T2 cognitive irritation, $b=.41,95 \%$ Bayesian CI [.16, .70], and a significant positive relationship with T2 learning, $b=.39,95 \%$ Bayesian CI [.18, .57]. T2 cognitive irritation was significantly negatively related to $\mathrm{T} 2 \mathrm{em}$ ployee resilience, $b=-.10,95 \%$ Bayesian CI [-.14, -.07], and $\mathrm{T} 2$ learning was significantly positively related to $\mathrm{T} 2$ employee resilience, $b=.05,95 \%$ Bayesian CI $[.001, .10]$.

The results of the indirect effects showed that $\mathrm{T} 1$ time pressure was significantly negatively related to $\mathrm{T} 2 \mathrm{em}-$ ployee resilience via T2 cognitive irritation, $b=-.05$, $95 \%$ Bayesian CI [-.19, -.04], which was also the case for T1 job complexity, $b=-.04,95 \%$ Bayesian CI [-.07, -.02]. Thus, Hypotheses $2 \mathrm{a}$ and $2 \mathrm{~b}$ were supported. Further, T1 time pressure showed no significant positive association with T2 employee resilience via T2 learning, $b=-.00$, $95 \%$ Bayesian CI [-.01, .01], but a positive indirect effect of $\mathrm{T} 1$ job complexity on $\mathrm{T} 2$ resilience via $\mathrm{T} 2$ learning was detectable, $b=.02,95 \%$ Bayesian CI [.001, .05]. Thus, Hypothesis $3 \mathrm{a}$ had to be rejected and Hypothesis $3 \mathrm{~b}$ was supported.

\section{Additional Analyses}

To further underpin the validity of our analyses, we additionally examined the curvilinear associations of time pressure and job complexity on both $\mathrm{T} 2$ learning and $\mathrm{T} 2$ cognitive irritation. This approach rests on previous research findings related to detected curvilinear associations of challenge demands on strain and positive outcomes, such as work engagement (e.g., Schmitt et al., 2015; Teuchmann et al., 1999). We calculated the squared product of time pressure and job complexity and entered these product terms in the regression model while simultaneously controlling for the linear predictors. In this model, we only found one significant effect of squared job complexity on T2 learning, $b=-.28,95 \%$ Bayesian CI [-.47, -.12]. In this model, the linear effect of job complexity and $\mathrm{T} 2$ learning remained significant, $b=$ 
Table 2. Indirect and total effects from Bayesian time-lagged path model with Bayesian credibility intervals

\begin{tabular}{|c|c|c|c|}
\hline & \multirow[b]{2}{*}{ Estimate $(P S D)$} & \multicolumn{2}{|c|}{ Bayesian $95 \% \mathrm{Cl}$} \\
\hline & & LL & UL \\
\hline \multicolumn{4}{|l|}{ a-paths } \\
\hline T1 Time Pressure $\rightarrow$ T2 Learning & $-.06(.08)$ & -.18 & .10 \\
\hline T1 Time Pressure $\rightarrow$ T2 Cognitive Irritation & $.53(.11) * \star$ & .40 & .76 \\
\hline T1 Job Complexity $\rightarrow$ T2 Learning & $.39(.11)^{\star \star}$ & .18 & .57 \\
\hline T1 Job Complexity $\rightarrow$ T2 Cognitive Irritation & $.41(.13)^{\star \star}$ & .16 & .70 \\
\hline \multicolumn{4}{|l|}{ b-paths } \\
\hline T2 Learning $\rightarrow$ T2 Resilience & $.05(.03)^{\star}$ & .001 & .10 \\
\hline T2 Cognitive Irritation $\rightarrow$ T2 Resilience & $-.10(.02)^{\star \star}$ & -.14 & -.07 \\
\hline \multicolumn{4}{|l|}{ Stability } \\
\hline R1 Resilience $\rightarrow$ R2 Resilience & $.74(.04)^{\star \star}$ & .66 & .81 \\
\hline \multicolumn{4}{|l|}{ Covariations } \\
\hline T1 Time Pressure $\leftrightarrow$ T1 Job Complexity & $.25(.04)^{\star \star}$ & .18 & .31 \\
\hline T2 Learning $\leftarrow \rightarrow T 2$ Cognitive Irritation & $-.25(.10) \star$ & -.45 & -.06 \\
\hline \multicolumn{4}{|l|}{ Direct effects } \\
\hline T1 Time Pressure $\rightarrow$ T2 Resilience & $.04(.04)$ & -.03 & .11 \\
\hline T1 Job Complexity $\rightarrow$ T2 Resilience & $.05(.04)$ & -.04 & .15 \\
\hline \multicolumn{4}{|l|}{ Indirect effects } \\
\hline T1 Time Pressure $\rightarrow$ T2 Learning $\rightarrow$ T2 Resilience & $-.00(.01)$ & -.01 & .01 \\
\hline T1 Time Pressure $\rightarrow$ T2 Cog. Irritation $\rightarrow$ T2 Resilience & $-.05(.02)^{\star *}$ & -.19 & -.04 \\
\hline T1 Job Complexity $\rightarrow$ T2 Learning $\rightarrow$ T2 Resilience & $.02(.01)^{*}$ & .001 & .05 \\
\hline T1 Job Complexity $\rightarrow$ T2 Cog. Irritation $\rightarrow$ T2 Resilience & $-.04(.02)^{\star \star}$ & -.07 & -.02 \\
\hline \multicolumn{4}{|l|}{ Total effects } \\
\hline T1 Time Pressure $\rightarrow$ T2 Resilience & $-.02(.04)$ & -.10 & .04 \\
\hline T1 Job Complexity $\rightarrow$ T2 Resilience & $.02(.05)$ & -.05 & .12 \\
\hline
\end{tabular}

Note. The table shows unstandardized estimates. $\mathrm{Cl}=$ confidence interval; $\mathrm{LL}=$ lower limit, $\mathrm{UL}=$ upper limit. ${ }^{*} p<.05,{ }^{*} p<.001$ (two-sided testing). On all variables in the model, we regressed sex and age, with only two significant estimates for time pressure regressed on age $(95 \% \mathrm{Cl}:[.01 ; .07], p<.001)$ and job complexity regressed on age (95\% Cl: $[.03 ; .09], p<.001)$.

2.45, $95 \%$ Bayesian CI [1.39, 3.78]. No other significant main effect of squared time pressure and squared job complexity was found.

\section{Discussion}

This study examined the effects of work stressors classified as challenges (i.e., time pressure, job complexity) on employee resilience and explored potential mediators to explain the assumed effects. Based on previous literature (e.g., Crane \& Searle, 2016), we proposed a positive direct effect of time pressure and job complexity on employee resilience, but we did not find this effect. Suppressor effects might play a role in these nonsignificant findings. Previous studies examined the favorable effects of challenge demands with entering challenge and hindrance demands in the same model (e.g., Cavanaugh et al.,
2000; LePine et al., 2005), such that the negative variation of challenge demands might be masked by simultaneously entered hindrance demands (i.e., suppressor effect). Previous scholars explicitly tested this potential suppressor effect and showed that the favorable effects of challenge demands were present only when the negative variation was controlled (Baethge et al., 2018; Widmer et al., 2012). This means that a positive effect of challenge stressors (i.e., time pressure, job complexity) on employee resilience might be present only when the effects of hindrance demands are considered simultaneously (cf. Crane \& Searle, 2016). Another explanation might rest on potential mean-level changes in job demands and employee resilience. Previous scholars showed that the dynamic effects of variables over time are essential to be considered beyond models with static effects only, as such approaches provide a more holistic view on how changes in one variable (i.e., job demands) contributes to subsequent changes in another variable 
(i.e., employee resilience) (Rigotti et al., 2014; Schulz et al., 2020). Thus, the direct effects between challenge demands and employee resilience may be more likely when mean-level changes are taken into consideration.

Moreover, appraisal processes may represent a missing component inherent in the challenge-hindrance model. Previous studies questioned the a priori classification of stressors into challenges and hindrances, demonstrating that individual appraisal processes are important to understand the proposed positive effects of challenge demands (e.g., Gerich, 2017; Webster et al., 2011). According to the SSR model (Crane, Searle et al., 2019), situation-focused, self-reflective practices - in addition to reappraisal processes, such as self-awareness - are important for understanding how stressors promote employee resilience. For example, cognitively appraising time pressure and job complexity as challenging might initiate an additional investment of trigger identification (i. e., the specific ability to identify situational triggers; Crane, Searle et al., 2019), enabling individuals to seek situations in which appraisals of time pressure and job complexity as challenging are likely (e.g., experienced time pressure in specific projects). Thus, appraisals of job demands as well as an examination of specific self-reflective practices may reflect important mechanisms for how demands considered to be challenges facilitate employee resilience (Crane, Searle et al., 2019; Kalisch et al., 2015). The results of our study highlight that the association of potential challenge demands with employee resilience is potentially more complex, and that further underlying mechanisms (e.g., appraisal processes, self-reflective practices) must be considered (cf. Crane, Searle et al., 2019).

Consistent with our assumption, time pressure and job complexity showed a negative indirect effect on employee resilience via cognitive irritation. Further, time pressure and job complexity showed a positive association with cognitive irritation, in support of previous research on challenge stressors (e.g., Cavanaugh et al., 2000; LePine et al., 2005). As stated by the stressor detachment model (Sonnentag \& Fritz, 2015), the time course of experienced work-related stressors is important. In particular, when stressors occur over a longer period, recovery experiences - an important resource to gaining and maintaining additional psychological resources such as resilience are restricted, resulting in a continued loss of resources (see also Hobfoll, 1989).

Our assumptions that time pressure and job complexity are positively related to employee resilience via learning (H3) were partially supported. Job complexity showed a positive indirect effect on employee resilience via learning. This finding underpins theoretical assertions by the SSR model (Crane, Searle et al., 2019), such that demands trigger a process of learning and these learning experiences contribute to an increase of resilience. We additionally found a curvilinear association of job complexity with learning, indicating that, with an increase in job complexity, the positive association with learning gradually decreases. Such a gradual decrease in learning is consistent with assertions from activation theory (Gardner \& Cummings, 1988), which states that individuals show an optimal level of activation when job demands are on a moderate level.

Time pressure did not show a relationship with employee resilience via (synchronous) learning. Further, contrary to previous findings (e.g., Prem et al., 2017), time pressure showed no association with learning. A potential explanation could be the time interval we used in our study. For example, Baethge et al. (2018) showed that time pressure was positively linked with work engagement within 1 workday, whereas constantly higher time pressure over 6-8 weeks was related to less work engagement. Further, based on research about recovery processes (see Sonnentag et al., 2010), if stressors persist over a longer period without sufficient recovery experiences, this might restrict opportunities for learning and personal growth. Thus, the chosen 2-month time-lagged design could explain why we were unable to find any effects of time pressure on changes in employee resilience via learning.

\section{Theoretical Implications}

The results of our study promote the idea that everyday stressors affect employee resilience via learning and cognitive irritation. Thus, our study extends the theoretical considerations of the SSR model (Crane, Searle et al., 2019). This supports the initial idea of the SSR, namely, that, besides traumatic events, everyday stressors can also influence employee resilience. We showed that experiences of learning represent a pathway for how job demands (i. e., job complexity) facilitate employee resilience.

Our second contribution relates to the meaning of demands considered as challenges within the challengehindrance stressor framework (Cavanaugh et al., 2000). Previous research often suggested that challenge stressors generally promote personal gain or growth (Podsakoff et al., 2007), whereas our findings highlight the meaning of pathways, such as learning and cognitive irritation, to determine whether such demands are linked to favorable outcomes. The results showed variability in the way demands considered to be challenges are linked to employee resilience. These findings underpin recent doubts regarding a priori assumptions about the proposed positive effects of job demands considered as challenges (Mazzola \& Disselhorst, 2019). Instead of an a priori 
classification, stronger focus should be put on mechanisms (i.e., learning, strain) that explain how demands affect positive psychological outcomes, such as employee resilience.

Our findings contribute to recent assertions of the JD-R theory (Bakker \& Demerouti, 2017) by examining learning as a fruitful pathway for how job demands are associated with experiences of personal growth, such as an increase in employee resilience. The findings of this study underpin the assumption that job demands are not exclusively linked to a health-impairment process; rather, we demonstrated that a health-impairment and motivational process can be triggered simultaneously. Thus, we contribute to an expanded understanding of these proposed processes within JD-R theory, as we were able to show that the motivational process is not exclusively triggered by resources, but also by job demands, such as job complexity.

\section{Practical Implications}

We can also derive some practical implications for the workplace. First, exposure to work-related stressors, such as job complexity, can trigger a process of personal learning, increasing employee resilience. However, over 2 months, time pressure and job complexity also drained employee resilience via a strain process. Managers should be aware that exposure to stressors is not necessarily linked to an increase in employee resilience, and they should do their best to build a work environment of learning that offers the utilization of resources to cope with workplace challenges (cf. Kuntz et al., 2016). Especially in the presence of chronic time pressure and job complexity, managers should offer intervention programs to assist employees in facilitating detachment and boundary management (cf. Sonnentag \& Fritz, 2015). Second, organizations should offer targeted intervention programs to help individuals increase their resilience. Individuals who have a higher resilience are more able to resist and cope with difficult working conditions (Britt et al., 2016). However, managers should still be aware that an accumulation of work stressors over a longer period can elicit a psychological impairment process and decrease personal resources, such as employee resilience through overloading the coping system (cf. Crane \& Searle, 2016).

\section{Limitations and Directions for Future Research}

Because time pressure and job complexity were the only stressors we used in this study, we cannot generalize to other types of stressors. Future studies should address this issue with the investigation of additional (challenge) stressors and how they might affect employee resilience (e.g., workload, responsibility, performance pressure). Linking to this, future studies could further examine curvilinear associations of job demands within challengehindrance research on both positive and negative working outcomes. This approach may additionally contribute to an extended JD-R model, in which curvilinear effects of job demands are considered for both motivational and strain processes (cf. Bakker \& Demerouti, 2017). Moreover, an expanded examination of additional (challenge) demands helps to reconcile the recently questioned assertions about the proposed favorable effects of challenge demands and contributes to an extended elaborated understanding within challenge-hindrance stress research (Mazzola \& Disselhorst, 2019).

Note that we classified time pressure and job complexity a priori as challenge demands, based on previous research findings (LePine et al., 2005). However, recent research raised some questions about this a priori classification, as it neglects the important meaning of appraisal processes related to stressful conditions (Webster et al., 2011), as proposed by the transactional model of stress (Lazarus \& Folkman, 1984). Therefore, future studies that use the challenge-hindrance framework should consider a qualitatively extended theoretical approach related to the classification of job demands into challenges and hindrances. Such an extension might lie in considering initial appraisal processes related to job demands (Mazzola \& Disselhorst, 2019).

A methodological drawback concerns the time-lagged mediation model employed. We examined all mediations with only two timepoints, thereby failing to capture a complete mediation model over three waves of data (cf. Crane \& Searle, 2016). To more accurately test mediation models, it is recommended to use full longitudinal data to decrease the risk of committing logical misapprehension of research findings and to use mediation models in a sustained way (Selig \& Preacher, 2009). Moreover, we used a time-lagged design with a time interval of 2 months to investigate our hypotheses. Time-lagged designs have an advantage compared to cross-sectional data analysis; however, we could not investigate causality or reversed effects in our design (cf. Abbas \& Raja, 2019). Accordingly, future studies with a fully longitudinal approach may want to consider latent change score modeling addressing the incremental value of dynamic changes in variables to gain a more holistic view among job demands, mediators, and employee resilience (cf. Schulz et al., 2020). In addition, assessing objective parameters (e.g., physiological indicators) might represent a promising approach, as such parameters represent a robust founda- 
tion for individuals' resilience (Kalisch et al., 2015). For example, future studies could assess an individual's cortisol level over several measuring time points, as cortisol modulates the appraisal system and can be a valid objective indicator of resilience mechanisms (Kalisch et al., 2015).

Finally, in this study results of the logistic regression indicated an attrition bias related to sex, time pressure, and job complexity between responders and nonresponders. The occurrence of attrition is common within longitudinal research and may narrow the study findings (cf. Miller \& Hollist, 2007). Even though we controlled for sex in our analyses, the higher amount of experienced time pressure and lower amount of job complexity among the responders may have narrowed the effects on $\mathrm{T} 2$ learning, cognitive irritation, and resilience.

\section{Conclusion}

This study served to expand our understanding of pathways and antecedents of employee resilience within organizational stress research. We showed that challenge stressors indirectly affect employee resilience via a strain and learning path. Whereas time pressure and job complexity influenced employee resilience via cognitive irritation, only job complexity was positively related to employee resilience via learning. Experienced time pressure drained employees' resilience via triggering a strain path and was, therefore, linked only with a process of resource loss. This investigation showed pathways concerning why and how prominent challenge stressors affect employee resilience and contributed to a refinement in the understanding of workplace resilience. Organizations should be aware of the potential effects of experienced stressors on employee resilience and do their best to build a working environment that supports people in an ongoing process of learning and personal growth.

\section{Electronic Supplementary Material}

The electronic supplementary material is available with the online version of the article at https://doi.org/ $10.1026 / 0932-4089 / \mathrm{a} 000363$

ESM 1. Figure E1 and E2

ESM 2. Table E1: Supplementary analyses of indirect and total effects from Bayesian time-lagged path model without control variables

\section{References}

Abbas, M., \& Raja, U. (2019). Challenge-hindrance stressors and job outcomes: The moderating role of conscientiousness. Journal of Business and Psychology, 34(2), 189-201. https:// doi.org/10.1007/s10869-018-9535-z

Baer, M., \& Oldham, G. R. (2006). The curvilinear relation between experienced creative time pressure and creativity: Moderating effects of openness to experience and support for creativity. Journal of Applied Psychology, 91(4), 963 - 970. https://doi.org/ 10.1037/0021-9010.91.4.963

Baethge, A., Deci, N., Dettmers, J., \& Rigotti, T. (2019). "Some days won't end ever": Working faster and longer as a boundary condition for challenge versus hindrance effects of time pressure. Journal of Occupational Health Psychology, 24(3), 322 - 332. https://doi.org/10.1037/ocp0000121

Baethge, A., Vahle-Hinz, T., Schulte-Braucks, J., \& van Dick, R. (2018). A matter of time? Challenging and hindering effects of time pressure on work engagement. Work \& Stress, 32(3), $228-$ 247. https://doi.org/10.1080/02678373.2017.1415998

Bakker, A. B., \& Demerouti, E. (2014). The job demands-resources model: State of the art. Journal of Managerial Psychology, 22(3), 309 - 328. https://doi.org/10.1108/02683940710733115

Bakker, A., \& Demerouti, E. (2017). Job demands-resources theory: Taking stock and looking forward. Journal of Occupational Health Psychology, 22(3), 273-285. https://doi.org/ http://dx.doi.org/10.1037/ocp0000056

Brislin, R. W. (1970). Back translation for cross-cultural research. Journal of Cross-Cultural Psychology, 1(3), 185-216.

Britt, T. W., Shen, W., Sinclair, R. R., Grossman, M. R., \& Klieger, D. M. (2016). How much do we really know about employee resilience? Industrial and Organizational Psychology, 9(02), 378-404. https://doi.org/10.1017/iop.2015.107

Carver, C. S. (1998). Resilience and thriving: Issues, models, and linkages. Journal of Social Issues, 54(2), 245-266. https://doi. org/10.1111/0022-4537.641998064

Cavanaugh, M. A., Boswell, W. R., Roehling, M. V., \& Boudreau, J. W. (2000). An empirical examination of self-reported work stress among U.S. managers. Journal of Applied Psychology, 85(1), 65-74. https://doi.org/10.1037//0021-9010.85.1.65

Connor, K. M., \& Davidson, J. R. T. (2003). Development of a new resilience scale: The Connor-Davidson Resilience Scale (CDRISC). Depression and Anxiety, 18(2), 76 - 82. https://doi.org/10. 1002/da.10113

Crane, M. F., Boga, D., Karin, E., Gucciardi, D. F., Rapport, F., Callen, J., \& Sinclair, L. (2019). Strengthening resilience in military officer cadets: A group-randomized controlled trial of coping and emotion regulatory self-reflection training. Journal of Consulting and Clinical Psychology, 87(2), 125-140. https:// doi.org/10.1037/ccp0000356

Crane, M. F., Kho, M., Kangas, M., Griffin, B., Karin, E., Earl, J. K., \& Harris, C. B. (2020). Strengthening resilience in over 50's: A nested clustered-randomized controlled trial of adaptive systematic self-reflection. Anxiety, Stress, \& Coping, 33(6), $623-$ 641. https://doi.org/10.1080/10615806.2020.1768375

Crane, M. F., \& Searle, B. J. (2016). Building resilience through exposure to stressors: The effects of challenges versus hindrances. Journal of Occupational Health Psychology, 21(4), 468-479. https://doi.org/10.1037/a0040064

Crane, M. F., Searle, B. J., Kangas, M., \& Nwiran, Y. (2019). How resilience is strengthened by exposure to stressors: The systematic self-reflection model of resilience strengthening. Anxiety, Stress, \& Coping, 32(1), 1-17. https://doi.org/10.1080/ 10615806.2018.1506640 
Crawford, E. R., LePine, J. A., \& Rich, B. L. (2010). Linking job demands and resources to employee engagement and burnout: A theoretical extension and meta-analytic test. Journal of Applied Psychology, 95(5), 834-848. https://doi.org/10.1037/ a0019364

Flinchbaugh, C., Luth, M. T., \& Li, P. (2015). A challenge or a hindrance? Understanding the effects of stressors and thriving on life satisfaction. International Journal of Stress Management, 22(4), 323 -345. https://doi.org/10.1037/a0039136

Ford, M. T., Matthews, R. A., Wooldridge, J. D., Mishra, V., Kakar, U. M., \& Strahan, S. R. (2014). How do occupational stressorstrain effects vary with time? A review and meta-analysis of the relevance of time lags in longitudinal studies. Work \& Stress, 28(1), 9 -30. https://doi.org/10.1080/02678373.2013.877096

Gardner, D. G., \& Cummings, L. L. (1988). Activation theory and task design: Review and reconceptualization. Research in Organizational Behavior, 10, $81-122$.

Gerich, J. (2017). The relevance of challenge and hindrance appraisals of working conditions for employees' health. International Journal of Stress Management, 24(3), 270-292. https://doi.org/10.1037/str0000038

Gross, J. J. (2015). Emotion regulation: Current status and future prospects. Psychological Inquiry, 26(1), 1-26. https://doi.org/ 10.1080/1047840X.2014.940781

Guthier, C., Dormann, C., \& Voelkle, M. C. (2020). Reciprocal effects between job stressors and burnout: A continuous time metaanalysis of longitudinal studies. Psychological Bulletin, 146(12), 1146 - 1173. https://doi.org/10.1037/bul0000304

Hao, S., Hong, W., Xu, H., Zhou, L., \& Xie, Z. (2015). Relationship between resilience, stress and burnout among civil servants in Beijing, China: Mediating and moderating effect analysis. Personality and Individual Differences, 83, 65-71. https://doi. org/10.1016/j.paid.2015.03.048

Hargrove, M. B., Nelson, D. L., \& Cooper, C. L. (2013). Generating eustress by challenging employees. Helping people savor their work. Organizational Dynamics, 42(1), 61 -69. https://doi.org/ 10.1016/j.orgdyn.2012.12.008

Hobfoll, S. E. (1989). Conservation of resources: A new attempt at conceptualizing stress. American Psychologist, 44(3), 513 - 524. https://doi.org/10.1037/0003-066X.44.3.513

Hoijtink, H., Gu, X., Mulder, J., \& Rosseel, Y. (2019). Computing bayes factors from data with missing values. Psychological Methods, 24(2), 253-268. https://doi.org/10.1037/met0000 187

Hu, T., Zhang, D., \& Wang, J. (2015). A meta-analysis of the trait resilience and mental health. Personality and Individual Differences, 76, 18 -27. https://doi.org/10.1016/j.paid.2014.11.039

Kalisch, R., Müller, M. B., \& Tüscher, O. (2015). A conceptual framework for the neurobiological study of resilience. Behavioral and Brain Sciences, 38, 1-21. https://doi.org/10.1017/ S0140525X1400082X

Kaplan, D., \& Depaoli, S. (2015). Bayesian structural equation modeling. In R.H. Hoyle (Ed.), Handbook of Structural Equation Modeling (pp. $650-673$ ). Guilford.

Karasek, R. A. (1979). Job demands, job decision latitude, and mental strain: Implications for job redesign. Administrative Science Quarterly, 24(2), 285-308. https://doi.org/10.2307/ 2392498

Kim, M., \& Beehr, T. A. (2020). Thriving on demand: Challenging work results in employee flourishing through appraisals and resources. International Journal of Stress Management, 27(2), $111-125$. https://doi.org/10.1037/str0000135

King, D. D., Newman, A., \& Luthans, F. (2016). Not if, but when we need resilience in the workplace. Journal of Organizational Behavior, 37(5), 782 - 786. https://doi.org/10.1002/job.2063
Kuntz, J. R. C., Naswall, K., \& Malinen, S. (2016). Resilient employees in resilient organizations: Flourishing beyond adversity. Industrial and Organizational Psychology, 9(2), 456-462. https://doi.org/10.1017/iop.2016.40

Lazarus, R. S., \& Folkman, S. (1984). Stress, appraisal and coping. Springer.

LePine, J. A., Podsakoff, N. P., \& LePine, M. A. (2005). A metaanalytic test of the challenge stressor-hindrance stressor framework: An explanation for inconsistent relationships among stressors and performance. Academy of Management Journal, 48(5), 764-775. https://doi.org/10.5465/AMJ.2005. 18803921

Liu, C., \& Li, H. (2018). Stressors and stressor appraisals: The moderating effect of task efficacy. Journal of Business and Psychology, 33(1), 141 -154. https://doi.org/10.1007/s10869016-9483-4

Mazzola, J. J., \& Disselhorst, R. (2019). Should we be "challenging" employees? A critical review and meta-analysis of the challenge-hindrance model of stress. Journal of Organizational Behavior, 40(8), 949 - 961. https://doi.org/10.1002/job.2412

Meichenbaum, D. H. (1985). Stress inoculation training. Pergamon.

Meichenbaum, D. H., \& Deffenbacher, J. L. (1988). Stress inoculation training. The Counseling Psychologist, 16(1), 69-90. https://doi.org/10.1177/0011000088161005

Miller, B. M., \& Hollist, C. S. (2007). Attrition bias. In N. Salkind (Ed.), Encyclopedia of measurement and statistics (pp. 57-60). Sage. Retrieved from https://doi.org/http://digitalcommons. unl.edu/famconfacpub/45

Mohr, G., Rigotti, T., \& Müller, A. (2005). Irritation - Ein Instrument zur Erfassung psychischer Beanspruchung im Arbeitskontext. Skalen- und Itemparameter aus 15 Studien [Irritation - an instrument assessing mental strain in working contexts. Scale and item parameters from 15 studies]. Zeitschrift für Arbeitsund Organisationspsychologie, 49(1), 44-48. https://doi.org/10. 1026/0932-4089.49.1.44

Morgeson, F. P., \& Humphrey, S.E. (2006). The Work Design Questionnaire (WDQ): Developing and validating a comprehensive measure for assessing job design and the nature of work. Journal of Applied Psychology, 91(6), 1321-1339. https://doi. org/10.1037/0021-9010.91.6.1321

Muthèn, L. K., \& Muthèn, B. O. (1998-2014). Mplus user's guide (7th ed.). Author.

Podsakoff, N. P., LePine, J. A., \& LePine, M. A. (2007). Differential challenge stressor-hindrance stressor relationships with job attitudes, turnover intentions, turnover, and withdrawal behavior: A meta-analysis. Journal of Applied Psychology, 92(2), 438 454. https://doi.org/10.1037/0021-9010.92.2.438

Podsakoff, P. M., MacKenzie, S. B., Lee, J. Y., \& Podsakoff, N. P. (2003). Common method biases in behavioral research: A critical review of the literature and recommended remedies. Journal of Applied Psychology, 88(5), 879 - 903. https://doi.org/ 10.1037/0021-9010.88.5.879

Porath, C., Spreitzer, G., Gibson, C., \& Garnett, F. G. (2012). Thriving at work: Toward its measurement, construct validation, and theoretical refinement. Journal of Organizational Behavior, 33(2), 250 - 275. https://doi.org/10.1002/job.756

Prem, R., Ohly, S., Kubicek, B., \& Korunka, C. (2017). Thriving on challenge stressors? Exploring time pressure and learning demands as antecedents of thriving at work. Journal of Organizational Behavior, 38(1), 108-123. https://doi.org/10. 1002/job.2115

Prem, R., Paškvan, M., Kubicek, B., \& Korunka, C. (2018). Exploring the ambivalence of time pressure in daily working life. International Journal of Stress Management, 25(1), 35 - 43. https://doi. org/10.1037/str0000044 
Rees, C. S., Breen, L. J., Cusack, L., \& Hegney, D. (2015). Understanding individual resilience in the workplace: The international collaboration of workforce resilience model. Frontiers in Psychology, 6, 1 - 7. https://doi.org/10.3389/fpsyg.2015.00073

Rigotti, T., Korek, S., \& Otto, K. (2014). Gains and losses related to career transitions within organisations. Journal of Vocational Behavior, 84(2), 177 -187. https://doi.org/10.1016/j.jvb.2013. 12.006

Sarubin, N., Gutt, D., Giegling, I., Böhner, M., Hilbert, S., Krähenmann, O., Wolf, M., Jobst, A., Sabab, L., Rujescu, D., Falkai, P., \& Padberg, F. (2015). Erste Analyse der psychometrischen Eigenschaften und Struktur der deutschsprachigen 10-und 25-Item Version der Connor-Davidson Resilience Scale (CD-RISC) [First analysis of the 10- and 25-item German version of the ConnorDavidson Resilience Scale (CD-RISC)]. Zeitschrift für Gesundheitspsychologie, 23(3), 112-122. https://doi.org/10.1026/ 0943-8149/a000142

Schmitt, A., Ohly, S., \& Kleespies, N. (2015). Time pressure promotes work engagement: Test of illegitimate tasks as boundary condition. Journal of Personnel Psychology, 14(1), 28 - 36. https://doi.org/10.1027/1866-5888/a000119

Schulz, A. D., Schöllgen, I., Wendsche, J., Fay, D., \& Wegge, J. (2020). The dynamics of social stressors and detachment: Long-term mechanisms impacting well-being. International Journal of Stress Management. Advance online publication. https://doi.org/10.1037/str0000216

Selig, J. P., \& Preacher, K. J. (2009). Mediation models for longitudinal data in developmental research. Research in Human Development, 6(2-3), 144-164. https://doi.org/10. 1080/15427600902911247

Semmer, N. K., Zapf, D., \& Dunckel, H. (1999). Instrument zur stressbezogenen Tätigkeitsanalyse ISTA [Instrument for stressoriented job analysis]. In H. Dunckel (Ed.), Handbuch psychologischer Arbeitsanalyseverfahren (pp. 179-204). vdf Hochschulverlag.

Sonnentag, S., \& Fritz, C. (2015). Recovery from job stress: The stressor-detachment model as an integrative framework. Journal of Organizational Behavior, 36, $72-103$. https://doi.org/10. 1002/job.1924

Sonnentag, S., Kuttler, I., \& Fritz, C. (2010). Job stressors, emotional exhaustion, and need for recovery: A multi-source study on the benefits of psychological detachment. Journal of Vocational Behavior, 76(3), 355-365. https://doi.org/10.1016/j.jvb. 2009.06.005

Stegmann, S., Dick, R. Van, Ullrich, J., Charalambous, J., Menzel, B., Egold, N., \& Wu, T. T. (2010). Der Work Design Questionnaire - Vorstellung und erste Validierung einer deutschen Version [The Work Design Questionnaire - Introduction and validation of a German version]. Zeitschrift für Arbeits- und Organisationspsychologie, 54(1), 1-28. https://doi.org/10.1026/0942-4089/ a000002
Teuchmann, K., Totterdell, P., \& Parker, S. K. (1999). Rushed, unhappy, and drained: an experience sampling study of relations between time pressure, perceived control, mood, and emotional exhaustion in a group of accountants. Journal of Occupational Health Psychology, 4(1), 37 -54. https://doi.org/ 10.1037/1076-8998.4.1.37

Tugade, M. M., \& Fredrickson, B. L. (2004). Resilient individuals use positive emotions to bounce back from negative emotional experiences. Journal of Personality and Social Psychology, 86(2), 320 - 333. https://doi.org/10.1037/0022-3514.86.2.320

Webster, J. R., Beehr, T. A., \& Love, K. (2011). Extending the challenge-hindrance model of occupational stress: The role of appraisal. Journal of Vocational Behavior, 79(2), 505-516. https://doi.org/10.1016/j.jvb.2011.02.001

Widmer, P. S., Semmer, N. K., Kälin, W., Jacobshagen, N., \& Meier, L. L. (2012). The ambivalence of challenge stressors: Time pressure associated with both negative and positive well-being. Journal of Vocational Behavior, 80(2), 422 - 433. https://doi.org/ 10.1016/j.jvb.2011.09.006

Windle, G., Bennett, K. M., \& Noyes, J. (2011). A methodological review of resilience measurement scales. Health and Quality of Life Outcomes, 9(1), 1 - 8. https://doi.org/10.1186/1477-7525-9-8

Youssef, C. M., \& Luthans, F. (2007). Positive organizational behavior in the workplace. Journal of Management, 33(5), 774-800. https://doi.org/10.1177/01492063073056

\section{History}

Received September 23, 2020

Revision received May 27, 2021

Published online July 29, 2021

\section{Publication Ethics}

This study project was assessed and approved by the responsible Ethics Committee of the University of Mainz.

\section{Funding}

Open access publication enabled by Johannes Gutenberg University Mainz.

\section{ORCID}

Arian Kunzelmann

(iD)https://orcid.org/0000-0001-8864-9960

\section{Prof. Dr. Thomas Rigotti}

Institute of Psychology

Johannes Gutenberg University Mainz

Wallstraße 3

55122 Mainz

Germany

rigotti@uni-mainz.de 